\title{
Bronze Baby Syndrome: An Animal Model
}

\author{
GIULIO JORI, ELENA REDDI, AND FIRMINO F. RUBALTELLI \\ Department of Pediatrics, University of Padova, and Department of Biology and C.N.R. Center for the Physiology \\ and Biochemistry of Hemocyanins and Other Metallo-Proteins, University of Padova, Padova, Italy
}

\begin{abstract}
We evaluated the appropriateness of an animal model for the bronze baby syndrome. Ligation of the common bile duct in adult Wistar rats induces an accumulation of porphyrins and copper in the liver and a $\mathbf{2 0} \%$ conversion of protoporphyrin IX into $\mathrm{Cu}$ (II)-protoporphyrin IX. Upon irradiation of these animals with superblue lamps, the plasma content of $\mathrm{Cu}$ (II)-protoporphyrin increases by about $30 \%$. Cholestasis also increases the recovery of porphyrins in the urine, although light treatment of ligated rats further increases urinary porphyrin excretion. The spectroscopic changes induced by irradiation of sera of ligated rats are consistent with the formation of products that have the typical spectrum found in bronze baby syndrome patients, i.e. a reduced absorbance in the visible region and an increased absorption in near-UV and red spectral regions. The products responsible for the brown discoloration found in bronze baby syndrome seem to result from phototransformation of copper-porphyrins subsequent to an electron transfer between photoexcited bilirubin and the copper ion. (Pediatr Res 27: 22-25, 1990)
\end{abstract}

\section{Abbreviation}

BBS, bronze baby syndrome

The BBS was first described in 1972 by Kopelman et al. (1), who observed a newborn infant with a gray-brown discoloration after phototherapy for unconjugated hyperbilirubinemia. Subsequent reports (2-6) described the clinical aspects of this syndrome, whereas other studies attempted to clarify the biochemical mechanisms leading to BBS (7-9). In 1982, large amounts of porphyrins were demonstrated in sera of BBS patients (8). These were identified as $\mathrm{Cu}$-uro-, $\mathrm{Cu}$-copro-, and $\mathrm{Cu}$-protoporphyrin (9). In addition, large amounts of porphyrins were detected in sera of adult and pediatric patients with cholestatic disorders (10). The proposed mechanism for the onset of BBS invokes, first, the presence of cholestasis, causing elevated copper and porphyrin concentrations in serum, and second, hyperbilirubinemia and phototherapy (9-11). Cu-porphyrins undergo photodestruction, sensitized by bilirubin, to products that have generalized absorption in the near UV and red spectral regions and therefore are responsible for the brown discoloration (9-11).

To shed further light on the mechanisms of development of this syndrome, we evaluated an animal model of BBS using Wistar rats subjected to ligation of the common bile duct. This strain of animals was chosen because in preliminary experiments we observed a consistent serum level of both conjugated and unconjugated bilirubin after common bile duct ligation. The

Received March 15, 1989; accepted August 3, 1989.

Correspondence and reprint requests Prof. F. F. Rubaltelli, Department of Pediatrics, University of Padova Via Giustiniani, 335128 Padova, Italy. results of these experiments were similar with those obtained by using heterozygous Gunn rats (12).

\section{MATERIALS AND METHODS}

Chemicals. Bilirubin IX was purchased from Serva (Heidelberg, FRG) and used without further purification. Its concentration was evaluated by absorbance measurements at $460 \mathrm{~nm}$ using a molar extinction coefficient $164000 \mathrm{M}^{-1} \mathrm{~cm}^{-1}$ (ethanol solution) (13). All the free base porphyrins used were obtained from Porphyrin Products (Logan, UT) and converted into their Cu(II) derivatives by reaction with cupric acetate (14). SDS was the product of Merck (Darmstadt, FRG). All other chemicals were commercial products of at least analytical grade.

In vivo studies. In all our experiments, male Wistar rats (Ditta Morini, Reggio Emilia, Italy) between 3 and 9 mo old weighing between 250 and $350 \mathrm{~g}$ were used. Preliminary experiments showed that the body content of endogenous porphyrins is sex dependent and generally larger for older rats. The rats were housed in standard cages with free access to tap water and normal dietary food, except for a controlled low content of copper.

The rats were divided into four groups: 1) Control rats were kept in metabolic cages, where urine and feces were collected at 24-h intervals. They were killed by exposure to ether, and blood and liver samples were quickly removed. The liver was stored at $-17^{\circ} \mathrm{C}$, whereas the blood was heparinized and the plasma was collected by 15 -min centrifugation at $3000 \mathrm{rpm}$. 2) Rats whose bile duct was ligated under pentothal anesthesia. No significant mortality resulted from this operation. After ligation, the rats were kept in metabolic cages for up to $96 \mathrm{~h}$ with urine and feces collection each $24 \mathrm{~h}$. They were then killed and samples of blood and liver were removed and treated as described for the animals of group 1. 3) Rats with ligated bile duct that were kept in metabolic cages for $48 \mathrm{~h}$ and then irradiated for $24 \mathrm{~h}$ as described below. At selected times after irradiation, the rats were killed and the blood and liver were treated as for group 1 animals. Urine was collected before and during irradiation. 4) Rats that were kept in metabolic cages for $48 \mathrm{~h}$ and subsequently exposed to light for $24 \mathrm{~h}$ with collection of urine. After the phototherapy, the rats were killed and the blood and liver were treated as for group 1 animals.

Irradiation procedure. The rats in the metabolic cages were subjected to whole body irradiation by means of two superblue fluorescent lamps (Sylvania, Waltham, MA), which were symmetrically placed on opposite sides of the cage. The lamps had an emission maximum at $460 \mathrm{~nm}$ and a half-band width of 40 $\mathrm{nm}$. The light fluence, at the level of the irradiated animals, was $1.2 \mathrm{~W} / \mathrm{m}^{2}$, as assessed with a radiometer. The fluence was periodically controlled during the phototreatment.

Analysis of porphyrins. Before analysis, the plasma and urine samples were diluted with known volumes of $2 \%$ aqueous SDS to obtain an absorbance less than 0.1 at both 400 and $620 \mathrm{~nm}$. The solution was centrifuged for $10 \mathrm{~min}$ at $3000 \mathrm{rpm}$ and the supernatant was collected and used for fluorescence analysis. Tissues $(100-200 \mathrm{mg})$ were homogenized in a Potter vessel with 
$4 \mathrm{~mL}$ of $2 \%$ SDS. After $10 \mathrm{~min}$ centrifugation at $3000 \mathrm{rpm}$ the supernatant was further diluted with $2 \%$ SDS to an absorbance less than 0.1 at 400 and $620 \mathrm{~nm}$ and then assayed spectrophotoflourimetrically.

The porphyrin content in biologic fluids and tissue homogenetes was quantified using an MPF 4 Perkin-Elmer (Pomona, CA) apparatus. All samples were excited at $400 \mathrm{~nm}$ and the fluorescence emitted at wavelengths at more than $600 \mathrm{~nm}$ was recorded. For fluorescence excitation measurements, the emission monochromator was set at $620 \mathrm{~nm}$ and the excitation spectrum in the 310 - to $460-\mathrm{nm}$ interval was recorded. The fluorescence intensity values were converted into porphyrin concentration by interpolation with a calibration plot built with known amounts of porphyrin. The values for porphyrin concentrations essentially refer to protoporphyrin IX. HPLC analysis of selected serum, urine, and tissue extracts showed that protoporphyrin accounted for at least $90 \%$ of total porphyrin recovery. Therefore, although there is some variability in the fluorescence yield among different porphyrins (15), the error introduced into our data should be minimal, because such differences tend to disappear when the individual porphyrins are in a monomeric state and in an identical microenvironment (16); in our samples, all porphyrins are embedded into the hydrophobic interior of SDS micelles. This assumption is supported by the observation that under our analytical conditions there is a linear relationship between porphyrin concentration and fluorescence intensity.

A major source of uncertainty in the estimation of porphyrins by fluorescence analysis of tissue homogenates is the presence of a wavelength-dependent scattering background (17). To evaluate this, we performed parallel analyses of our samples by fluorescence excitation at $395 \mathrm{~nm}$ and emission at $620 \mathrm{~nm}$ : a good agreement was found between the two sets of data. Under these conditions, a linear correlation is observed between fluorescence intensity and porphyrin concentration even in the presence of biologic materials (18).

In some experiments, the plasma content of $\mathrm{Cu}(\mathrm{II})$-protoporphyrin IX was determined by HPLC according to Mascanzoni et al. (19). The HPLC apparatus was a Perkin-Elmer series 4 instrument, which was equipped with a Waters C-18 column (Waters Associates, Milford, MA). The serum $(0.2 \mathrm{~mL})$ was diluted 5-fold with methanol before loading on the column. The eluent system included two phases: initial elution was made with solvent A (acetonitrile/tetrabutylammonium phosphate $/ 2.5 \mathrm{mM}$ methanol, $3: 2: 1, \mathrm{vol} / \mathrm{vol} / \mathrm{vol}$ ) with a change to phase B (methanol/tetrabutylammonium phosphate $2.5 \mathrm{mM}, 9: 1$, vol/vol) after $15 \mathrm{~min}$. The eluate was continuously monitored for its absorbance at $400 \mathrm{~nm}$ and the area of the single peaks was estimated by a computer-controlled integrator.

Measurement of copper. The content of copper in the biologic fluids and the tissue homogenates (prepared by the procedures described previously) was measured by atomic absorption spectroscopy using a Perkin-EImer $4000 \mathrm{AS}$ spectrophotometer. The instrument had been previously calibrated with an aqueous solution of cupric acetate at a concentration of $0.1 \mathrm{ug} / \mathrm{mL}$.

Measurement of bilirubin. The content of bilirubin in the biologic fluids and tissue homogenates in 2\% aqueous SDS was determined by spectrophotofluorimetry. The samples containing the bilirubin as a monomer in the SDS micelles were excited at $460 \mathrm{~nm}$ and fluorescence emission was recorded between 480 and $600 \mathrm{~nm}$. Bilirubin concentration was obtained by interpolation of the fluorescence intensity values with a suitable calibra- tion plot built with known solutions of bilirubin in aqueous SDS (20).

Unconjugated bilirubin in the plasma was estimated by absorbance determinations at $546 \mathrm{~nm}$ after reaction with sulfanilic acid at 20-25 (21) Control studies showed that under our experimental conditions the absorbance is linearly related with the bilirubin concentration up to at least $25 \mathrm{mg} / \mathrm{dL}$.

$B B S$ case. A serum sample from a term infant who had developed BBS after phototherapy for hyperbilirubinemia was obtained on the 5 th $\mathrm{d}$ of life. The serum was analyzed for bilirubin and porphyrin content by the above specified procedure before and after irradiation of serum with the superblue lamps.

Statistical analysis. Student's $t$ test for grouped data was used to compare the values found in ligated and control rats.

\section{RESULTS}

In vivo studies. The concentrations of porphyrins, bilirubin, and $\mathrm{Cu}(\mathrm{II})$ ions from the plasma, urine, and liver of control Wistar rats (group 1) were in agreement with literature data (Table 1) (22). The corresponding values for irradiated rats (group 4) showed no significant differences. In Figures $1-3$ we report the porphyrin concentrations in bile-duct ligated (group 2) and ligated plus irradiated (group 3 ) rats. It is evident that after irradiation, the plasma porphyrin concentration increases, whereas there is a decrease of the concentration in the liver. It is important to note that all the concentrations from urine have been estimated for individual animals during the $24 \mathrm{~h}$ subsequent to irradiation and the equivalent time period for bile duct-ligated unirradiated rats. The same groups of animals were kept in metabolic cages throughout the experiment. However, for plasma and liver, the individual animals were killed at predetermined times before analysis.

HPLC analyses of plasma taken from rats at $48 \mathrm{~h}$ after ligation of the bile duct showed that about $20 \%$ of protoporphyrin IX

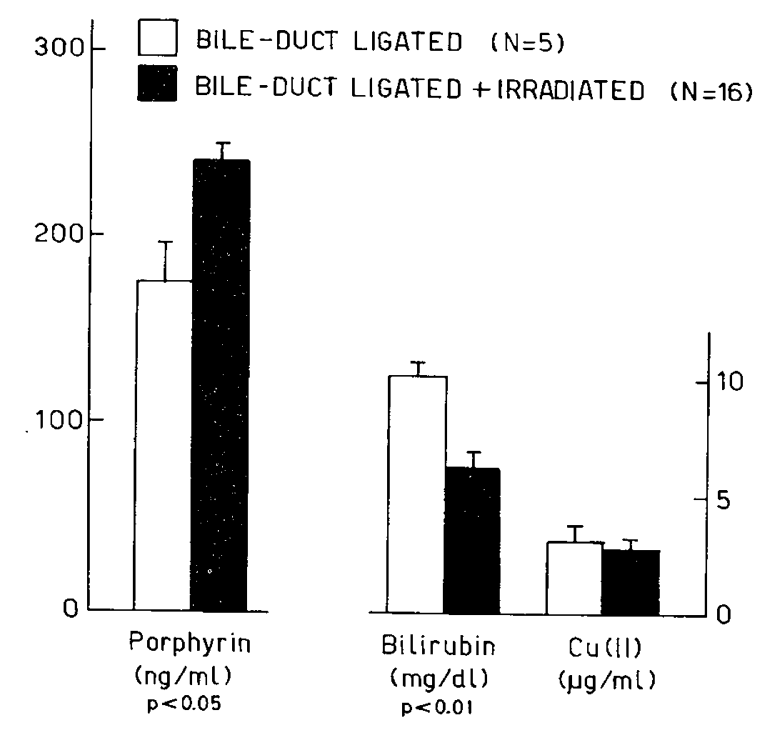

Fig. 1. Concentrations of porphyrin, bilirubin, and $\mathrm{Cu}(\mathrm{Il})$ ions in plasma samples of rats $72 \mathrm{~h}$ after bile duct ligation (group 2) and in similar rats irradiated with superblue lamps for the last $24 \mathrm{~h}$ (group 3).

Table 1. Concentration of porphyrin, bilirubin, and Cu(II) ions in plasma, urine, and liver samples of control rats*

\begin{tabular}{cllc}
\hline Rats $(n)$ & \multicolumn{1}{c}{ Porphyrin } & \multicolumn{1}{c}{ Bilirubin } & $\mathrm{Cu}(\mathrm{II})$ \\
\hline Plasma (6) & $24.0 \pm 9.4(\mathrm{ng} / \mathrm{mL})$ & $0.2 \pm 0.06(\mathrm{mg} / \mathrm{dL})$ & $1.2 \pm 0.2(\mu \mathrm{g} / \mathrm{mL})$ \\
Urine $(8)$ & $0.10 \pm 0.02(\mathrm{mg} / 24 \mathrm{~h})$ & $5.7 \pm 0.94(\mathrm{mg} / 24 \mathrm{~h})$ & $0.41 \pm 0.06(\mu \mathrm{g} / 24 \mathrm{~h})$ \\
Liver (3) & $39.5 \pm 0.5(\mathrm{ng} / \mathrm{g})$ & $2.7 \pm 0.4(\mathrm{mg} / \mathrm{g})$ & $2.9 \pm 0.6(\mu \mathrm{g} / \mathrm{g})$ \\
\hline
\end{tabular}

\footnotetext{
* All values represent mean $\mathrm{SD}$.
} 


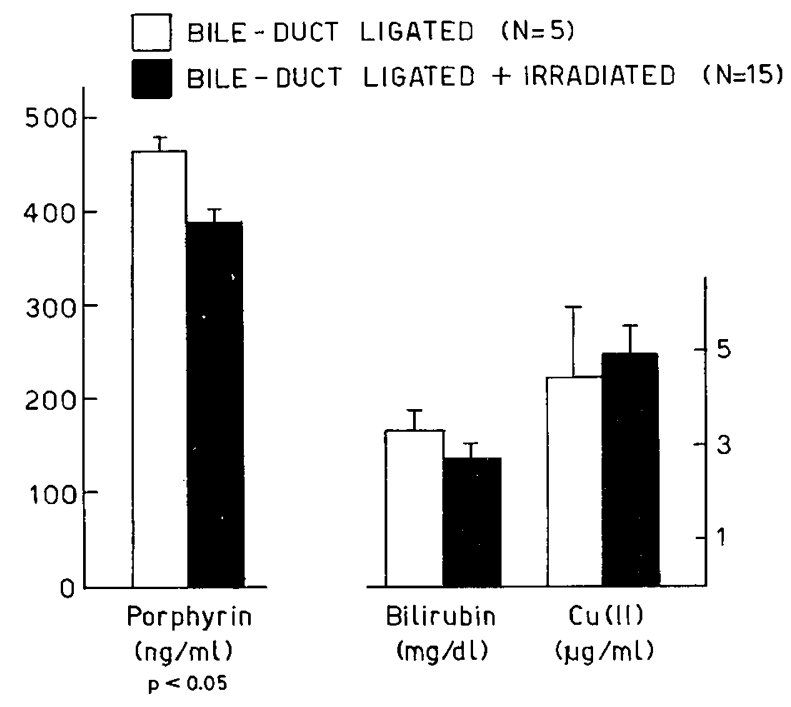

Fig. 2. Concentrations of porphyrin, bilirubin, and $\mathrm{Cu}(\mathrm{II})$ ions in livers of rats $72 \mathrm{~h}$ after bile duct ligation (group 2) and in similar rats irradiated with superblue lamps for the last $24 \mathrm{~h}$ (group 3) rats.

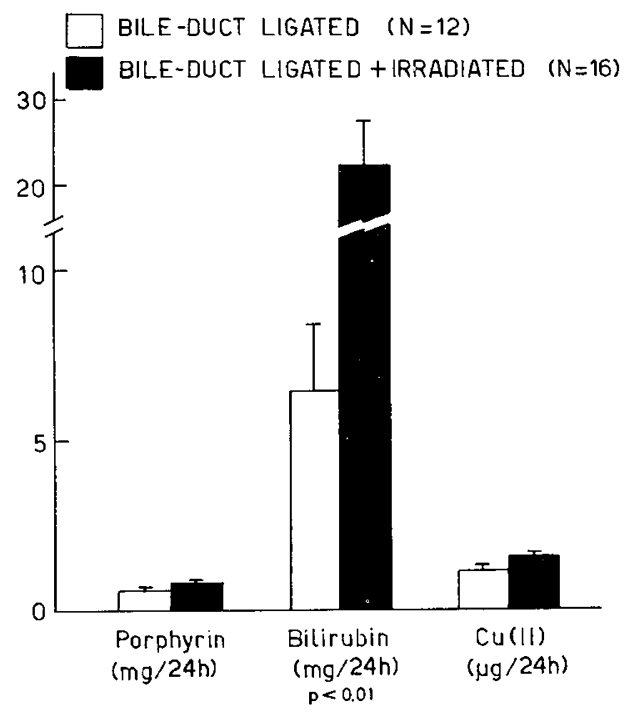

Fig. 3. Concentrations of porphyrin, bilirubin, and $\mathrm{Cu}(\mathrm{II})$ ions in urine of rats $72 \mathrm{~h}$ after bile duct ligation (group 2) and in similar rats irradiated with superblue lamps for the last $24 \mathrm{~h}$ (group 3) rats.

had been converted into the corresponding $\mathrm{Cu}$ (II)-protoporphyrin, whereas only traces of $\mathrm{Cu}(\mathrm{II})$-protoporphyrin were found in plasma of control rats. After $24 \mathrm{~h}$ irradiation of the ligated rats, the plasma content of $\mathrm{Cu}(\mathrm{II})$-protoporphyrin increased by about $30 \%$. Again, no formation of $\mathrm{Cu}$ (II)-protoporphyrin was detected upon blue light irradiation of rats whose bile duct had not been ligated.

In vitro studies. The plasma obtained from four rats whose common bile duct had been ligated for $48 \mathrm{~h}$ were pooled and irradiated by the superblue lamps. The absorption spectra recorded at 3,9 , and $15 \mathrm{~h}$ after the beginning of the irradiation are shown in Figure 4. The content of bilirubin decreased from 9.32 to $5.73 \mathrm{mg} / \mathrm{dL}$, whereas the content of protoporphyrin $(0.29 \mathrm{ng} /$ $\mathrm{mL}$ ) remained essentially unchanged.

Exposure of the plasma to light brings about a substantial decrease of the bilirubin concentration, which is in agreement with the known photolability of this compound (13). This fact explains the photo-induced decrease of absorbance at wavelengths less than $550 \mathrm{~nm}$ (Fig. 4). At the same time, one can observe a gradual enhancement of the absorbance in the red spectral regions (at $>580 \mathrm{~nm}$ ). Essentially identical spectral modifications have been previously obtained upon irradiation of the bilirubin/Cu(II)-protoporphyrin system (11) and were ascribed to a photosensitized degradation of $\mathrm{Cu}(\mathrm{II})$-protoporphyrin. Actually, the content of the latter compound was decreased in irradiated plasma from 0.08 to $0.03 \mathrm{ng} / \mathrm{mL}$.

Analogously, with in vitro 24-h irradiation of the serum of a neonate who had developed BBS, we observed the appearance of a dark brown color with absorption spectral changes overlapping those reported in Figure 4. These modifications were accompanied by the decrease of both bilirubin $(15.44$ to $9.93 \mathrm{mg} / \mathrm{dL})$ and $\mathrm{Cu}(\mathrm{II})$-protoporphyrin $(0.17$ to $0.09 \mathrm{ng} / \mathrm{mL})$. The photoprocesses were accelerated by the addition of fresh bilirubin to the irradiated serum, whereas the addition of either protoporphyrin or its cupric derivative had no significant effect.

\section{DISCUSSION}

The exact nature of the pigments responsible for the bronze color of the skin in neonates developing BBS is still debatable. The involvement of photoisomerization and photooxidation products of bilirubin $(7,23)$ and biliverdin-related compounds (24) has been proposed. However, previous studies from our laboratory $(8,9)$ pointed out the presence of abnormally high serum concentrations of copper-porphyrins in those hyperbilirubinemic neonates developing BBS upon phototherapy; bluelight irradiation of these porphyrins in the presence of bilirubin yields brown photoproducts whose spectral features closely resemble those typical of sera isolated from BBS patients $(10,24)$.

Copper-porphyrins can be spontaneously formed in the presence of large amounts of $\mathrm{Cu}(\mathrm{II})$ ions and free base porphyrins due to the large affinity of the tetrapyrrolic macrocycle for a variety of metal ions (14). The excess $\mathrm{Cu}(\mathrm{II})$ ions could overcome the binding capacity of endogenous serum and liver proteins. Such a mechanism for the onset of BBS is in agreement with the known deranged liver function and cholestasis in BBS patients $(6,23)$, whereas the need for the simultaneous presence of cholestasis, hyperbilirubinemia, and phototherapy would explain the rare occurrence of this syndrome.

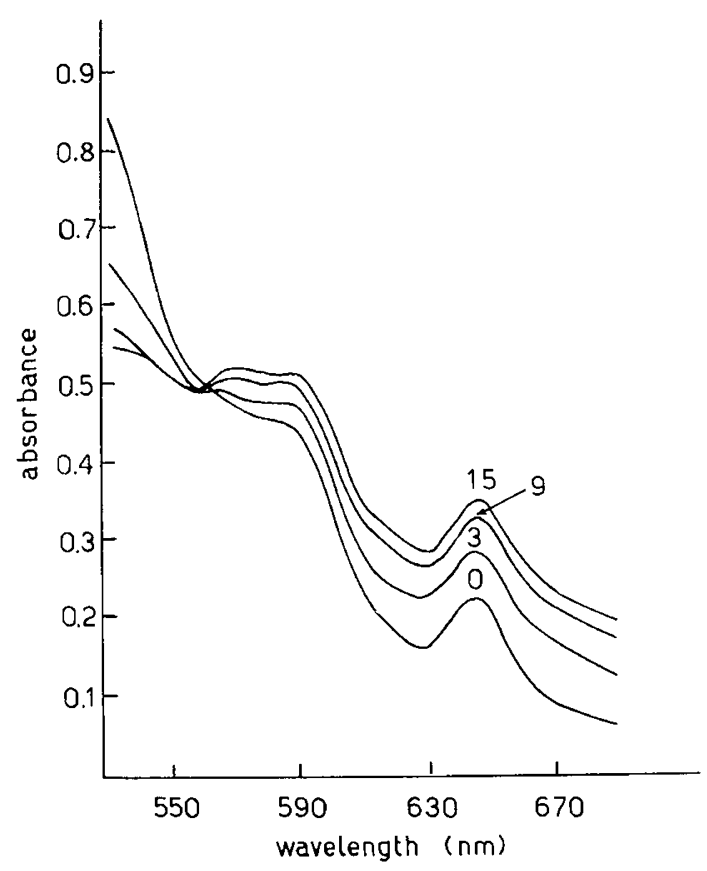

Fig. 4. Visible absorption spectrum of pooled plasma samples obtained from four rats $48 \mathrm{~h}$ after ligation of common bile duct. The plasma samples were irradiated for $0,3,9$, or $15 \mathrm{~min}$. 
To check the validity of our hypothesis, we developed an animal model where rats were artificially made cholestatic and hyperbilirubinemic. Under these conditions, the accumulation of both copper and porphyrins (mainly protoporphyrin) in the serum and liver is observed. HPLC analysis of the porphyrins extracted from the sera indicates that about $20-22 \%$ of the accumulated protoporphyrin is transformed into the $\mathrm{Cu}$ derivative. Similarly, significant amounts of $\mathrm{Cu}(\mathrm{II})$-protoporphyrin and smaller amounts of $\mathrm{Cu}(\mathrm{II})$-uroporphyrin are present in the serum of a BBS patient. No detectable amounts of copper-porphyrins are found in the sera of either normal or hyperbilirubinemic but not cholestatic neonates (10). The data obtained in the present investigation clearly show that the ligation of the common bile duct is necessary for the formation of $\mathrm{Cu}$ (II)-porphyrins. Only small amounts of the porphyrins are eliminated in the urine (Fig. 3 ), which is in agreement with the predominant formation of hydrophobic derivatives, such as protoporphyrin. Actually, poorly water-soluble porphyrins are largely eliminated via the bile-gut pathway, whereas only very polar porphyrins (such as uroporphyrin) are cleared from the organism in the urine (25).

The spectroscopic changes induced by irradiation of sera obtained from both ligated rats and a BBS patient are consistent with a decrease in the concentration of bilirubin and the formation of products with an increased absorption in the near-UV and red spectral region. Similar observations were made by other authors (24). The photodegradation of bilirubin is a well-described process (26) leading to photooxidized pyrroles and bilirubin isomers, all of which have a reduced absorbance in the visible region and lack any absorbance at wavelengths of more than $600 \mathrm{~nm}$. However, porphyrin photoproducts with new absorption bands in the red region have been reported (27); in particular, oxidized polymeric derivatives of porphyrins display a brown color. Our previous in vitro studies (11) suggest that the phototransformation of copper-porphyrins is sensitized by the initially photoexcited bilirubin.

Thus, the HPLC analysis of irradiated plasma demonstrates that porphyrin itself is rather photostable, whereas $\mathrm{Cu}(\mathrm{II})$-protoporphyrin undergoes a significant drop in concentration. It is likely that the observed formation of brown products reflects a photodegradation of $\mathrm{Cu}(\mathrm{II})$-protoporphyrin subsequent to an electron transfer between photoexcited bilirubin and the copper ion (11).

In conclusion, the studies with our animal model indicate that the induction of cholestasis by bile duct ligation causes a large increase in plasma and liver content of porphyrins, including the formation of $\mathrm{Cu}(\mathrm{II})$-protoporphyrin. Subsequent irradiation increases the plasma concentration of $\mathrm{Cu}(\mathrm{II})$-protoporphyrin with the simultaneous appearance of spectroscopic changes reproducing those observed upon irradiation of the sera obtained from BBS neonates.

\section{REFERENCES}

1. Kopelman AE, Brown AE, Odell GB 1972 The "bronze" baby syndrome: a complication of phototherapy. J Pediatr 81:446-450
2. Sharma RK, Ente PJ, Collip VT, Maddaiah VT, Rezvani I 1973 A complication of phototherapy in the newborn: The "bronze baby." Clin Pediatr $12: 231-234$

3. Weitz R 1975 Das Bronze-Baby Syndrom. Eine Komplikation der Phototherapie. Padiatr Prax 16:173-179

4. Clark CF, Torii S, Hamamoto Y, Kaito H 1976 The "bronze baby" syndrome: postmortem data. J Pediatr 88:461-464

5. Radermacher EH, Noirfalise A, Hornchen H, Maier D, Bigalke KH 1977 Das Bronze-baby Syndrom. Eine Komplikation der Phototherapie. Klin Padiatr 189:1379-1384

6. Tan KL, Jacob E 1982 The bronze baby syndrome. Acta Paediatr Scand 71:409-414

7. Onishi S, Itoh S, Isobe K, Togari H, Kitoh H, Nishimurh Y 1982 Mechanism of development of bronze baby syndrome in neonates treated with phototherapy. Pediatrics 69:273-276

8. Jori G, Reddi E, Rubaltelli FF 1982 Bronze baby syndrome: evidence for increased serum porphyrin concentration. Lancet 1:1072

9. Rubaltelli FF, Jori G, Reddi E 1983 Bronze baby syndrome: a new porphyrin related disorder. Pediatr Res 17:327-330

10. Jori G, Reddi E, Rossi E, Rubaltelli FF 1983 Porphyrin metabolism in the "bronze" baby syndrome. In: Stern L, Bard H, Friis-Hansen B (eds) Intensive Care in the Newborn. Masson Publishing Inc., New York, pp 41-44

11. Rubaltelli FF, Jori G, Rossi E, Garbo G 1983 Bronze baby syndrome: new insights on bilirubin-photosensitization of copper-porphyrins. In: Rubaltelli FF, Jori G (eds) Neonatal Jaundice. New Trends in Phototherapy. Plenum Press, New York, pp 265-275

12. Pettenazzo A, Reddi E, Granati B, Camurri S, Zaramella P, Rubaltelli FF 1985 Cholestasis induced in Gunn rats as an experimental model of bronze baby syndrome. In: Bensasson RV, Jori G, Land EJ, Truscott TG (eds) Primary Photo-Processes in Biology and Medicine. NATO ASI Series. Plenum Press, New York, pp 421-424

13. Rubaltelli FF, Jori G 1979 Visible light irradiation of human and bovine serum albumin-bilirubin complex. Photochem Photobiol 29:991-1000

14. Buchler JW 1975 Static coordination of metalloporphyrins. In: Smith RM (ed) Porphyrins and Metalloporphyrins. Elsevier, Amsterdam, pp 179-231

15. Srivastava RC, Amand VD, Carper WR 1973 A fluorescence study of hematoporphyrin. Appl Spectrosc 27:444-449

16. Jori G, Spikes JD 1983 Photobiochemistry of porphyrins. In: Smith KC (ed) Topics in Photomedicine. Plenum Press, New York, pp 183-319

17. Pasternack RF 1973 Aggregation properties of water-soluble porphyrins. Ann NY Acad Sci 206:614-630

18. Cozzani I, Jori G, Reddi E, Granati B, Felice M, Tomio L 1981 Distribution of endogenous and injected porphyrins at the subcellular level in rat hepatocytes and in ascites hepatoma. Chem Biol Interactions 37:67-75

19. Mascanzoni C, Menegaldo E, Jori G 1987 Validation of the methodologies for the control of a hematoporphyrin preparation used in the photodynamic therapy of tumours. Med Biol Environm 15:73-79

20. Lamola AA, Eisinger J, Blumberg WE, Patel SC, Flores J 1979 Fluorimetric study of the partition of bilirubin among blood components. Anal Biochem 100:25-42

21. Heirwegh KPM, Blanckaert N 1982 Analytical chemistry of rubins. In: Heirwegh KPM, Brown SB (eds) Bilirubin, Vol 1, Chemistry. CRC Press Inc., Boca Raton, FL, pp 125-130

22. Mitruka BM, Rawnsley HM 1977 Clinical Biochemical and Hematological Reference Values in Normal Experimental Animals. Masson, New York

23. Meisel P, Jahrig D, Meisel M 1987 Detection of photobilirubin in urine of jaundiced infants supporting the diagnosis of 'bronze baby syndrome.' Clin Chim Acta 166:61-65

24. Purcell SM, Wians FH, Ackerman NB, Davis BM 1987 Hyperbiliverdinemia in the bronze baby syndrome. J Am Acad Dermatol 16:172-177

25. Marks GS 1969 Disorders of porphyrin metabolism. In: Marks GS (ed) Heme and Chlorophyll. Van Nostrand, London, pp 163-197

26. McDonagh AF, Ramonas L 1978 Jaundice phototherapy: microflow-cell photometry reveals rapid biliary response of Gunn rats to light. Science 201:829831

27. Whitten DG 1978 Photochemistry of porphyrins and their metal complexes in solution and organized media. Rev Chem Intermed 2:107-138 